\title{
Estudio de la discriminación auditiva en educación infantil en Valencia
}

\begin{abstract}
Resumen
Este estudio se centra en conocer en qué grado los tutores de $2^{\circ}$ ciclo de Educación Infantil de las escuelas públicas de Valencia (España) trabajan el lenguaje musical en sus alumnos, con el fin de analizar la importancia que le atribuyen a la estimulación auditiva temprana por medio del desarrollo de la discriminación de sonidos musicales y su didáctica. La investigación es cuantitativa-cualitativa, por encuesta con cuestionario, administrado a 95 tutores. Como resultado, se confirma la escasa estimulación que reciben los niños y la necesidad de ofertar más cursos de formación en didáctica musical para este colectivo docente.
\end{abstract}

\section{Palabras clave}

Escucha activa; educación musical; cognición; tutor de clase

Para citar este artículo / To cite this article / Pour citer cet article / Para citar este artigo

Botella-Nicolás, Ana María \& Peiró-Esteve, María de los Ángeles (2018). Estudio de la discriminación auditiva en educación infantil en Valencia. magis, Revista Internacional de Investigación en Educación, 10 (21), 13-34. doi: 10.11144/Javeriana.m10-21.edae 
Keywords

Active listening; musical education; cognition; tutor
Mots clés

Ecoute active ; éducation musicale ; cognition; tuteur de classe

\section{Palavras-chave}

Escuta ativa; educação musical; cognição; tutor de classe

\section{Abstract}

This study aims to know to what extent tutors of the $2^{\text {nd }}$ cycle of Early Childhood Education in the public schools of Valencia (Spain) work on the musical language of their students, in order to analyze the importance attributed to early auditory stimulation by means of the development of the discrimination of musical sounds and their teaching approach. The research is quantitative-qualitative, it was made following a questionnaire survey, which was answereed by 95 tutors. As a result, this papers confirms the scant stimulation received by children and the need to offer more training courses in musical pedagogy for this teaching group.

\section{Résumé}

Cette étude vise à connaître dans quelle mesure les tuteurs de deuxième siècle d'éducation infantile des écoles publiques de Valencia (Espagne) travaillent le langage musical avec leurs élèves, avec l'objectif d'analyser l'importance qu'ils le donnent à la stimulation auditive initiale au moyen du développement de la discrimination de sons musicaux de leur didactique. La recherche est quantitative-qualitative, par enquête avec un questionnaire, administré à 95 tuteurs. En tant que résulta, on confirme la pauvre stimulation sonore que les enfants reçoivent et le besoin de fournir plus de cours de formation en didactique musicale pour ce collectif d'enseignants.

\section{Resumo}

Este estudo busca conhecer em que grau os tutores de $2^{\circ}$ ciclo de Educação Infantil das escolas públicas de Valencia (Espanha) trabalham a linguagem musical em seus alunos, com o fim de analisar a importância que atribuem à precoce estimulação auditiva por meio do desenvolvimento da distinção de sons musicais e sua didática. A pesquisa é quantitativa-qualitativa, por enquete com questionário, administrado a 95 tutores. Como resultado, se confirma a escassa estimulação que recebem as crianças e a necessidade de oferecer mais cursos de formação em didática musical para este coletivo docente. 


\section{Introducción}

Es difícil ignorar la importancia que tiene la música en la educación infantil, ya sea como disciplina o como una actividad descriptiva para reforzar otras áreas de conocimiento (Giráldez, 1996; Ken Hui, 2006 citado en Bond, 2012) y para acompañar y amenizar alguna actividad no musical (Lahoza, 2012; Palacios, 2011). Muchos pedagogos desde principios del siglo XX, como Émile-Jacques Dalcroze, Justine Ward, Zoltán Kodály, Edgar Willems, Carl Orff, Maurice Martenot, Shinichi Suzuki, Jos Wuytack y Edwin Gordon, entre otros, que han seguido las directrices de la Escuela Nueva hasta la actualidad, han diseñado métodos o han aportado ideas metodológicas cuyos sistemas de enseñanza musical favorecen el aprendizaje musical por medio de la audición activa. Tal como argumenta Rolando Ángel-Alvarado (2017):

Las actividades enmarcadas en la audición activa promueven el desarrollo de las distintas capacidades que se le asignan al área de Broca en forma simultánea con la potenciación del ámbito emocional, por consiguiente, se estimulan los factores sensoriales, sensorio-motores y perceptivo-cognitivos (p. 4)

En los últimos años, ha habido un interés creciente por conocer las causas del pobre rendimiento académico que padecen los niños en la etapa educativa. Para algunos autores (Piñol-Castro, 1999; Schafer, 1975), el principal foco del problema es la deficiencia auditiva desde la infancia. Los niños desde el nacimiento están expuestos a una multitud de sonidos, lo que da lugar a una hiperestimulación del entorno y, con ello, incrementan el hábito de rechazarlos y no prestarles la suficiente atención. La consecuencia de esta mala audición da lugar a problemas de escucha y de concentración, siendo estas esenciales para el proceso de los aprendizajes académicos, el lenguaje, el cognitivo y las conductas sociales (Ibáñez-Martínez \& Muro-Jiménez, 2015). Para Rosina Uriarte (citada en Chaparro-Santana, 2010), es primordial la reeducación auditiva en aquellos niños y niñas que padecen un fracaso escolar, problemas de conducta o emocionales por ser la deficiencia auditiva el principal foco del problema.

Una de las capacidades idóneas a estimular en edades tempranas es la percepción auditiva, por medio de la discriminación de sonidos, por ser una de las primeras habilidades que se comienzan a adquirir en la primera infancia, incluso antes del nacimiento. Al final de la gestación, el feto tiene la habilidad de reconocer la voz de la madre, diferenciar voces femeninas de las masculinas, etc. (Christa Einspieler, Daniela Prayer \& Heinz Prechtl, 2012 citados en Ángel-Alvarado, 2017). Además, Luis Álvarez, Paloma González-Castro, José Carlos Núñez, Julio Antonio González-Pienda, David Álvarez y Ana Belén Bernardo (2007); Óscar Cañete-S (2006); Franz Zenker y José Juan Barajas de Prat (2003) consideran que la discriminación auditiva es una de las habilidades auditivas más relevantes en el proceso de aprendizaje, por ser la habilidad más idónea para reconocer los sonidos, ya que un sonido se aprende cuando se diferencia de otro.

Según recientes estudios en la neurociencia cognitiva (Botella-Nicolás \& Peiró-Esteve, 2016), la estimulación auditiva es crucial en los primeros seis años para el desarrollo intelectual y cognitivo y, en cierta medida, para el desarrollo integral del niño, en general. Durante esta etapa, también conocida como período crítico o sensitivo, se abren unas ventanas cerebrales óptimas para establecer las suficientes conexiones neuronales que serán la base del desarrollo de nuevos aprendizajes y habilidades futuras.
Descripción del artículo | Article description | Description de l'article | Artigo descrição

Este artículo de investigación, derivado del proyecto IEDUCARTS [Educational Innovation Project to Delve Into Renovation of Teaching Methodologies], agrupa las diferentes valoraciones de un estudio sobre el uso de las audiciones musicales en el $2^{\circ}$ ciclo de Educación Infantil de los colegios públicos de Valencia por los maestros generalistas. La investigación desarrollada es mixta y persigue un doble objetivo. Por una parte, analizar la didáctica y el grado de importancia que los tutores dan a la enseñanza musical, concretamente a la discriminación auditiva en su praxis. Por otra, examinar si su formación musical influye en su interés por estimular auditivamente a sus alumnos a partir de la música y, en consecuencia, si se sienten asesorados por el especialista de música. 
La creación de estas conexiones obedece a la neuroplasticidad que posee el cerebro durante su período de crecimiento. No obstante, Yurelis GinarteArias (2007); Fernando Jáuregui-Huerta, Joaquín García-Estrada, Rodrigo Ramos-Zúñiga y Sonia Luquín de Anda (2014) testifican que estas conexiones son ilimitadas, pero dependen de la estimulación sensorial recibida del ambiente. Así, pues, si al niño se le brinda esta estimulación, tendrá un florecimiento neuronal que fomentará la creación de nuevas sinapsis, lo cual puede producir éxitos escolares.

Además, a raíz de sus investigaciones, varios autores (Álvarez, González-Castro, Núñez, González-Pienda, Álvarez \& Bernardo, 2007; Pramling-Samuelsson, Carlsson, Olsson, Pramling \& Wallerstedt, 2009) han comprobado que estimular auditivamente por medio de actividades que propician la discriminación auditiva aumenta la capacidad de atención y, con ello, la concentración ante una tarea cognitiva.

En definitiva, conociendo la importancia de la estimulación auditiva en la etapa infantil, uno de los primeros objetivos que marca la educación auditiva es trabajar la discriminación auditiva con el fin de desarrollar las operaciones cognitivas como la atención y la memoria auditiva. No obstante, los tutores de las aulas de infantil no dedican suficiente tiempo para desarrollarla por medio de las audiciones musicales. Esther Ruiz-Palomo, Fernando Lara-Ortega y Rosa María Santamaría-Conde (2014) apuntan: "El desarrollo de la percepción auditiva es un contenido de gran importancia y, por lo que hemos podido observar de forma empírica, se trabaja muy poco en las aulas o se hace de forma poco adecuada" (p. 30).

Los aportes que presenta este artículo son el estudio de cómo, cuándo y cuánto se trabaja la discriminación auditiva en las aulas de infantil por los tutores, cuáles son los parámetros musicales más utilizados y en qué grado los maestros de Educación Infantil se sienten asesorados y guiados por los especialistas de música para llevarlo a la práctica.

\section{Marco teórico}

Según Maravillas Díaz-Gómez (2005) y María de los Ángeles López de la Calle-Sampedro (2009), el desarrollo del oído por medio de las actividades musicales propicia el medio óptimo para fomentar el desarrollo integral del niño. Las experiencias sonoro-musicales no solo contribuyen al desarrollo de la inteligencia musical sino también al resto de inteligencias, especialmente la corpóreo-kinestética y espacial. Además, favorecen la estimulación del lenguaje, la atención, la concentración, la coordinación motora, el seguimiento de instrucciones, la creatividad, las habilidades para sintetizar y analizar; para potenciar y desarrollar la expresión de emociones y sentimientos; y para prevenir diferentes patologías como dislexia, hipoacusia, TDAH [trastorno por déficit de atención e hiperactividad], TFAC [trastornos de las funciones auditivas centrales], TPAC [trastorno del procesamiento auditivo central], entre otras.

Víctor Estalayo-Alonso y María Rosario Vega-Martín (2005) publicaron un estudio que argumenta científicamente la necesidad de desarrollar la inteligencia auditiva-musical durante la infancia, no solo para llegar a tener un buen oído musical sino también para reconocer los fonemas de la lengua. Aseguran que, durante esta etapa, la capacidad de discriminar sonidos alcanza el grado máximo. Además, sustentan que, si no se logra un nivel ideal durante este período, hay muchas posibilidades de que no se consiga nunca. A partir de los 3 años se va acrecentando la dificultad para percibir y discriminar con nitidez todos los sonidos y, en consecuencia, es más costoso comprender y hablar un nuevo idioma con el paso del tiempo. 
Estos autores aseguran que una de las causas que agravan la falta de desarrollo de la inteligencia auditiva es la escasez de programas de estimulación auditiva desde el nacimiento, lo que influye directamente en el desarrollo integral del niño en diferentes áreas: lentitud en el procesamiento de lo que se escucha, dificultad para discriminar los sonidos, falta de uniformidad en los umbrales de percepción, algunas distorsiones debidas a puntas de hiperaudición que complican la comprensión y pueden causar tendencias depresivas, pobre lateralización auditiva, coordinación y direccionalidad, e hipersensibilidad y audición dolorosa ante algunos sonidos agudos.

María Julia Ibáñez-Martínez y María Belén Muro-Jiménez (2015) testifican que hay una demanda española e internacional de programas innovadores de estimulación auditiva que tengan como objetivo prevenir posibles trastornos de procesamiento auditivo central (TPAC) junto con el déficit atencional. Por ello, algunos de sus estudios se centran en diseñar y aplicar programas innovadores para analizar su impacto en el aprendizaje del niño. Estas autoras crearon el programa de procesamiento de la información auditiva, de desarrollo entrenamiento y rehabilitación PROCESA, el cual trabaja la discriminación auditiva por medio de actividades audiomusicales dentro del aula ordinaria de infantil, e incluye la programación didáctica del tutor. Advierten que para obtener resultados significativos es aconsejable dedicar "un mínimo de tres sesiones semanales de 35 a 40 minutos, de forma grupal o individualmente" (p. 144).

En definitiva, hay recientes estudios de casos aislados en el ámbito español e internacional sobre cómo una adecuada estimulación temprana en la vía auditiva centrada en el desarrollo de diferentes habilidades, en general (Magán-Hervás \& Gértrudix-Barrio, 2017), y de la discriminación auditiva, en particular (Brito-Martins, 2015), ayudan a mejorar el aprendizaje de la lectoescritura, el lenguaje y la comunicación en la etapa infantil con el uso de actividades audiomusicales.

Pero, centrándonos en el caso concreto que nos ocupa, hay una ausencia de investigaciones sobre cómo se está abordando la estimulación auditiva en infantil por medio del desarrollo de la discriminación auditiva en la Comunidad Autónoma de Valencia. Además, hay pocos estudios españoles (Díaz-Gómez, 2005; López de la Calle-Sampedro, 2009; Ruiz-Palomo, Lara-Ortega \& Santamaría-Conde, 2014) que evalúan el conocimiento musical que tienen los maestros de Educación Infantil y cómo lo utilizan en sus prácticas. Sin embargo, hay estudios sobre cómo está integrada la audición musical en las enseñanzas secundarias en la Provincia de Valencia (Gimeno-Romero, 2014).

\section{El lenguaje musical dentro del currículum infantil}

Antes de continuar, es conveniente argumentar que esta investigación solo se ciñó a lo estipulado por la LOE, Ley Orgánica 2/2006 de Educación (España, Jefatura del Estado, 2006), ya que, a pesar de haber sido reformada en algunos aspectos por la LOMCE Ley Orgánica 8/2013, de 9 de diciembre para la mejora de la calidad educativa (España, Jefatura del Estado, 2013), la educación infantil no ha tenido modificaciones en el currículum, respecto a la LOE. Por esta razón, la investigación se centró en esta última, ya que es la ley vigente que expone más detalladamente aquello que los maestros de educación infantil deben impartir en sus clases.

Así, pues, centrándose en el currículum de infantil, concretamente en la educación musical, en el artículo 14.5 de la citada ley, así como el artículo 5.3 y el artículo 6.1 del Real Decreto 1630/2006 (España, Jefatura del Estado, 2007) aluden como expresión musical a uno de los principales 
contenidos educativos a impartir en esta etapa dentro del área de lenguajes: comunicación y representación. Por consiguiente, el Decreto 38/2008 (España, Conselleria de Educación, Comunidad Valenciana, 2008) destaca el lenguaje musical como uno de los siete bloques de contenidos dentro del área de los lenguajes, y especifica la percepción auditiva como una de las capacidades a estimular por medio de la discriminación de sonidos y sus cualidades, entre otras.

A pesar de la importancia manifiesta de este lenguaje en el desarrollo integral del niño, la LOMCE, en el artículo 18, concede un valor escaso a la educación artística por ser una de las cuatro materias optativas de la educación primaria a elegir por la escuela. Por consecuencia, como la enseñanza musical depende de la oferta de los centros educativos, la presencia del maestro especialista de música en las aulas de infantil y primaria puede ser escasa.

A nuestro entender, este hecho evoca menos recursos y asesoramiento por parte de dicho especialista hacia los maestros de educación infantil. Por ello, es primordial conocer el grado en que los docentes trabajan el lenguaje musical en la etapa infantil y, concretamente, el valor que otorgan a la estimulación de la percepción auditiva mediante la discriminación auditiva de sonidos musicales para conocer la realidad de las aulas y prevenir futuros problemas educativos.

\section{Objetivos}

Teniendo en cuenta los aspectos mencionados, el objetivo principal de la investigación fue conocer la actitud y el conocimiento que los tutores del $2^{\circ}$ ciclo de educación infantil tienen sobre la educación musical auditiva para saber si en sus praxis trabajan la habilidad de discriminación auditiva por medio de las audiciones musicales para desarrollar el oído interno y la capacidad atencional.

Como consecuencia, la investigación se asentó sobre dos ejes de estudio:

1. Revisión bibliográfica y estudio histórico sobre la importancia de la estimulación auditiva mediante las audiciones musicales en la etapa infantil, en concreto entre 3 y 6 años, en el ámbito académico, psicopedagógico y neurológico.

2. Diseño, análisis y aplicación de un cuestionario diseñado para estudiar diferentes aspectos en torno a la profesionalidad que tienen los maestros generalistas de $2^{\circ}$ ciclo de esta etapa en los colegios públicos de Valencia para trabajar la escucha comprensiva mediante la discriminación auditiva por medio de las audiciones musicales.
Los aportes del presente artículo se centran en el segundo de los ejes citados, concretamente en tres de los ocho objetivos específicos que engloban esta fase:

I. Analizar el grado en que los maestros de educación infantil trabajan el $6^{\circ}$ bloque lenguaje musical del vigente Decreto 38/2008, en general, y la discriminación auditiva, en particular, con el fin de valorar su interés por la misma.

II. Describir la metodología que los maestros de educación infantil aplican para trabajar la escucha comprensiva a partir de la habilidad de discriminar sonidos musicales: la frecuencia con que trabajan cada parámetro musical, las actividades musicales que llevan a cabo, los soportes musicales utilizados y los estilos musicales y los materiales didácticos escogidos.

III. Valorar la ayuda que los maestros de esta etapa reciben del maestro especialista de música con el fin de ofrecer una educación musical de calidad a sus alumnos con mayor autonomía, seguridad y confianza.

\section{Metodología}

Este estudio es cuantitativo y cualitativo, y de carácter predominantemente descriptivo. Durante su proceso de diseño, fue validado por tres profesionales de diferentes campos educativos (enseñanza formal, enseñanza no formal y enseñanza universitaria), que aportaron ideas y rectificaciones en los ítems con el fin de ajustarse al objetivo principal al que se ceñía la investigación.

Las técnicas utilizadas para el análisis de los datos fueron las tablas cruzadas, la comparación de medias, el chi-cuadrado y las tablas de contingencias. El programa estadístico utilizado fue el IBM SPSS Statistics 22.

El cuestionario se compone de 42 ítems divididos en 5 dimensiones: caracterización de la muestra, perfil del docente, metodología, materiales y perfil del alumno con preguntas cerradas dicotómicas, politómicas o de elección múltiple y de filtro.

Los ítems utilizados para el estudio del primer objetivo fueron: un ítem politómico con una escala de diferencial semántico de cinco grados para analizar el nivel en que se trabaja el $6^{\circ}$ bloque lenguaje musical del vigente Decreto 38/2008 en las aulas de infantil, seguido de una pregunta abierta para argumentarlo; una pregunta dicotómica con el fin de determinar si la discriminación auditiva se incluye en la programación de aula y, por consecuencia, se añadieron ítems con el mismo formato para señalar cuánto tiempo se trabaja 
y un ítem de elección múltiple para identificar el momento del día en que se lleva a cabo. Por lo tanto, las respuestas obtenidas de tales ítems fueron claves para dividir la muestra en dos grupos: los maestros que trabajan el lenguaje musical (grupo 1) y aquellos que no lo llevan a la práctica (grupo 2 ), independiente de la posible praxis que los maestros especialistas de educación musical de primaria tengan en las aulas de infantil.

Con respecto al segundo objetivo, solamente se tuvo en cuenta el grupo 1 para analizar qué metodología se lleva a cabo para trabajar la escucha comprensiva por medio de la discriminación auditiva, ya que los tutores del grupo 2 se abstuvieron de contestar las preguntas pertinentes a este objetivo. Por consiguiente, se optó por un ítem politómico con la escala de respuestas de tipo diferencial semántico con cinco grados para analizar la frecuencia en la que se trabajan catorce parámetros musicales, ocho actividades musicales y cinco tipos de soportes musicales, seguido con un ítem de elección múltiple para identificar el estilo musical y los materiales más utilizados para trabajar esa habilidad.

Por último, el tercer objetivo se valoró siguiendo el mismo diseño que el anterior con la finalidad de identificar el grado de ayuda que los maestros de infantil (grupo 1) aseguran tener del maestro especialista de educación musical de primaria.

En cuanto a la población, se tuvieron en cuenta los centros públicos de Valencia en los que se imparte el $2^{\circ}$ ciclo de Educación Infantil. Según las guías correspondientes al curso 2014-2015 de la Conselleria de Educación, Investigación y Deporte de la Generalitat Valenciana, 84 colegios con un total de 368 cursos cumplían estas características. Seguidamente y partiendo de este dato, se aplicó la fórmula técnica de muestreo para poblaciones finitas, que dio como resultado que la muestra teórica estuviera compuesta por 61 tutores. Definitivamente, la muestra real quedó constituida por 95 tutores de 34 escuelas públicas de la ciudad de Valencia de los cuales el 95,8\% eran mujeres y el 65,2\% tenía edades entre 30 y 50 años (gráfico 1):

Gráfico 1

Edad

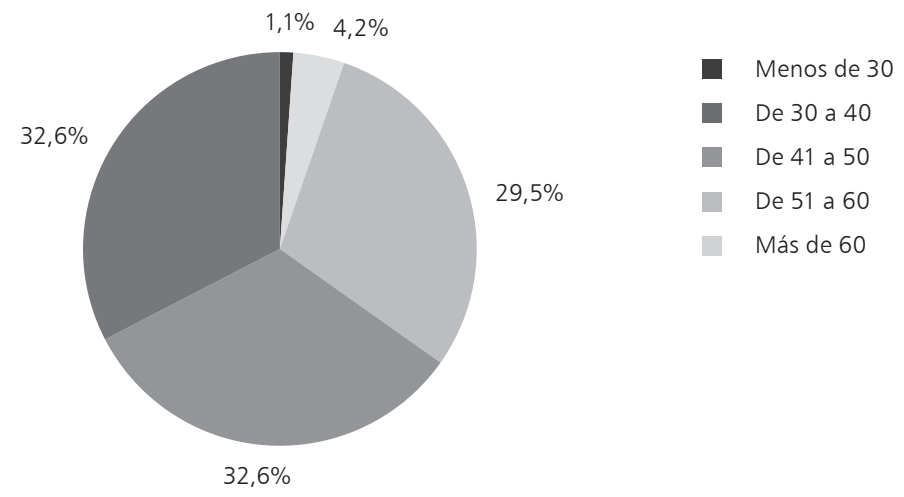

Fuente: elaboración propia

Con respecto a la experiencia docente, los porcentajes más elevados, $33,7 \%$ y $27,4 \%$, correspondían a los maestros que llevan trabajando entre 6 a 10 años y entre 11 a 15 años, respectivamente, en esta etapa educativa, seguidos del 22,1\% de maestros con 21 o más años de experiencia. Por tanto, 
la muestra estaba comprendida por tutores que tenían un conocimiento bastante convincente de la práctica educativa en la etapa de infantil.

Otro dato relevante fue conocer la distribución de los tutores por tramos educativos propios del ciclo. El mayor número de maestros encuestados (36,84\%) impartía docencia en el $2^{\circ}$ nivel ( 4 a 5 años), le siguen aquellos que atendían al $3^{\text {er }}$ nivel (5 a 6 años) con 32,63\% y, finalmente, el 30,53\% impartía sus enseñanzas en el 1 1er nivel (3 a 4 años). Este último nivel, con una media de 19,93 alumnos, era el que menos alumnado tenía por aula, seguido del $3^{\text {er }}(20,37)$ y del $2^{\circ}(22,03)$. Definitivamente, la media global de alumnos en el ciclo fue de 20,82. Este dato indica que la ratio estaba por debajo de lo estipulado por ley, lo cual proporciona una mejor atención educativa en esta etapa.

Otro punto relevante para la investigación fue conocer la formación musical inicial que todos ellos recibieron durante su formación universitaria en la Universidad de Valencia, partiendo del año en que terminaron sus estudios (tabla 1).

Tabla 1

La música como materia curricular en la especialidad infantil por diferentes planes de estudio de la Universitat de València y el porcentaje de tutores formados

\begin{tabular}{|c|c|c|c|}
\hline \multicolumn{2}{|c|}{ Plan de estudios } & \multirow{2}{*}{$\begin{array}{l}\text { Formación musical } \\
\text { Se implantó música / y música } / / \text { en } 2^{\circ} \text { y } 3^{\circ} \text { curso respectivamente, } \\
\text { con } 3 \text { horas lectivas cada una durante un cuatrimestre en todas las } \\
\text { especialidades de magisterio. }\end{array}$} & \multirow{2}{*}{\begin{tabular}{|c|} 
Tutores (\%) \\
11,6
\end{tabular}} \\
\hline \multirow{3}{*}{$\begin{array}{l}\text { Plan } 71 \text { de } \\
\quad \text { LGE }^{1}\end{array}$} & $1975-1980$ & & \\
\hline & 1981-1985 & $\begin{array}{l}\text { Apareció por primera vez la especialidad de preescolar; música se } \\
\text { cursaba solamente en el } 2^{\circ} \text { curso con una carga lectiva de } 3 \text { horas } \\
\text { y didáctica de la música quedó como optativa en el } 3^{\circ} \text { curso con } 3 \\
\text { horas lectivas. }\end{array}$ & 22,1 \\
\hline & 1986-1993 & $\begin{array}{l}\text { Se añadió la sensibilización musical del preescolar en } 3^{\circ} \text { curso con } 3 \\
\text { horas lectivas. }\end{array}$ & 16,8 \\
\hline $\begin{array}{l}\text { Plan } 93 \\
\text { LOGSE}^{2}\end{array}$ & 1994-1999 & $\begin{array}{l}\text { Se establecieron como materias troncales con } 6 \text { créditos cada } \\
\text { una: desarrollo de la expresión musical y su didáctica y expresión } \\
\text { musical en la educación. Además, entre las optativas ofertadas } \\
\text { para todas las especialidades, destacamos: investigación musical en } \\
\text { el aula; recursos didácticos; música, movimiento y dramatización; } \\
\text { musicoterapia en la educación especial; y desarrollo musical en la } \\
\text { educación infantil; educación auditiva en la escuela, entre otras. }\end{array}$ & 18,9 \\
\hline Plan $2000^{3}$ & $2000-2005$ & $\begin{array}{l}\text { Se cursa desarrollo de la expresión musical y su didáctica en } 1^{\circ} \text { curso } \\
\text { con } 6 \text { horas lectivas. }\end{array}$ & 20 \\
\hline
\end{tabular}

Fuente: elaboración propia

Así, pues, teniendo en cuenta que la mitad de tutores terminaron su carrera hace más de 22 años y un $20 \%$ se formaron en el Plan 2000, se puede decir que dicho profesorado puede tener dificultades para afrontar con éxito el desarrollo de una adecuada enseñanza musical en infantil.

1 Plan de estudios regulado por la Ley 14/1970, de 4 de agosto, General de Educación y Financiamiento de la Reforma educativa (LGE).

2 Este plan de estudios está regulado por la Ley Orgánica 1/1990, de 3 de octubre, de Ordenación General del Sistema Educativo (LOGSE).

3 Resolución de 21 de septiembre de 2000, de la Universidad de Valencia, por la que se ordena publicar el plan de estudios de Maestros-Especialidad de Educación Infantil, adaptado al Real Decreto 779/1998, de 30 de abril, y elaborado al amparo del Real Decreto de Directrices Generales Propias, 1440/1991, de 30 de agosto. 
Por otra parte, el 58,9\% de los maestros cursó algún curso de didáctica musical destinado a la formación del profesorado (gráfico 2), pero solamente el 10,5\% tenía estudios musicales por escuelas de música o conservatorios (gráfico 3).

Gráfico 2

Formación en didáctica musical en cursos destinados para los docentes

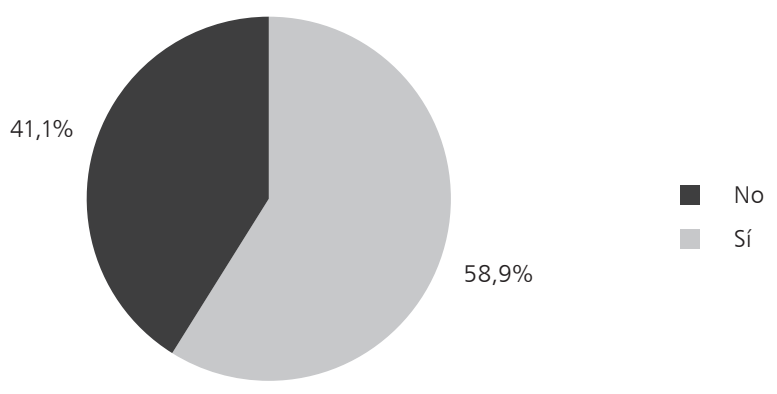

Fuente: elaboración propia

Gráfico 3

Estudios musicales formales y no formales

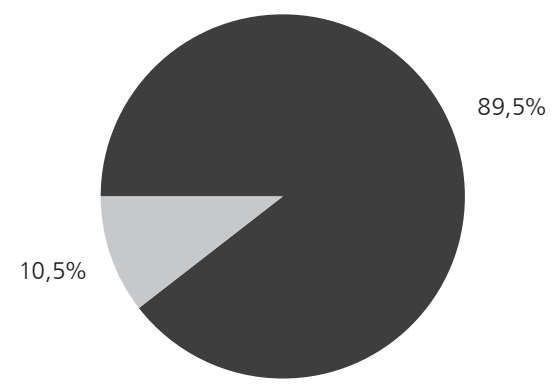

Fuente: elaboración propia

\section{Resultados y discusión}

En los siguientes apartados se desarrolla la descripción de los principales resultados obtenidos del cuestionario cumplimentado por el profesorado de segundo ciclo de educación infantil en los colegios públicos de Valencia y las principales valoraciones de cada objetivo específico.

\section{Valoraciones del objetivo I}

Este objetivo se centró en valorar la frecuencia con que los tutores de infantil imparten el lenguaje musical en su actividad docente e identificar la importancia que dan a la estimulación del oído interno y a la capacidad atencional por medio de la práctica de la discriminación auditiva y la escucha comprensiva de las audiciones musicales.

En primer lugar, el análisis pone de manifiesto que más de la mitad de la muestra (64,3\%) practica el lenguaje musical en su actividad docente. En cambio, menos de una cuarta parte de la misma (22,1\%) lo trabaja "casi nunca" o "nunca" (gráfico 4). 
Gráfico 4

Porcentaje de tutores que trabajan el lenguaje musical

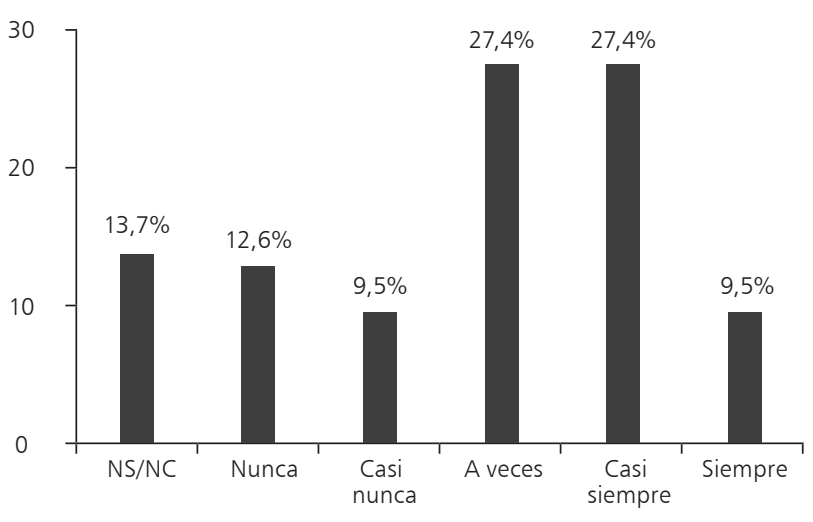

Fuente: elaboración propia

Los datos de la tabla 2 delatan varias conclusiones. Por un lado, se destaca que hay tutores que a pesar de que hubieran valorado los grados "casi nunca" y "a veces" (frecuencias de uso mínimo) se abstuvieron de continuar contestando el cuestionario ${ }^{4}$ (ambos con un porcentaje de 8,4\%). Por otro lado, las frecuencias de uso altas ("casi siempre" y "siempre") pertenecen al grupo 1 y son nulas en el grupo 2. Otro aspecto para tener en cuenta es que las frecuencias de uso bajas ("nunca" y "casi nunca") están mayoritariamente en el grupo 2 (el $12,6 \%$ y el $8,4 \%$, respectivamente). Además, más de la mitad de los tutores (18,9\% de 27,4\%) que aseguran trabajar "a veces" la música en su praxis docente están en el grupo 1.

Estos datos son significativos porque revelan que casi la totalidad del grupo 1 (el 63,2\%) ha marcado las frecuencias altas e intermedias, en cambio, la mayoría del grupo 2 (el 36,8\%) las frecuencias de uso bajas ("nunca" y "casi nunca"). Este dato es significativo porque denota el interés que los tutores tienen en practicar la música con sus alumnos (tabla 2).

Tabla 2

Frecuencias y porcentajes del grupo 1 y del grupo 2 en relación con su interés por impartir el lenguaje musical con sus alumnos

\begin{tabular}{l|c|c|c|c}
\cline { 2 - 5 } & \multicolumn{2}{c}{ Grupo 1 } & \multicolumn{2}{c}{ Grupo 2 } \\
\cline { 2 - 5 } & Frecuencia & Porcentaje (\%) & Frecuencia & Porcentaje (\%) \\
\hline Nunca & 0 & 0,0 & 12 & 12,6 \\
\hline Casi nunca & 1 & 1,1 & 8 & 8,4 \\
\hline A veces & 18 & 18,9 & 8 & 8,4 \\
\hline Casi siempre & 26 & 27,4 & 0 & 0,0 \\
\hline Siempre & 9 & 9,5 & 0 & 0,0 \\
\hline NS/NC & 6 & 6,3 & 7 & 7,4 \\
\hline Total (95) & 60 & 63,2 & 35 & 36,8 \\
\hline
\end{tabular}

Fuente: elaboración propia

4 Esta parte del cuestionario (desde el ítem 25 al 38) estaba reservada para los maestros de infantil que aseguraban impartir el lenguaje musical, al menos mínimamente, independiente de la entrada del maestro especialista de música en el aula. 
A continuación, se citan algunas de las reflexiones aportadas por los tutores (tabla 3).

Tabla 3

Valoraciones de los tutores acerca de su interés por impartir el lenguaje musical en su praxis

\begin{tabular}{|c|c|c|c|}
\hline Valoraciones & Cat & gorías & Comentario de los maestros \\
\hline \multirow{9}{*}{ 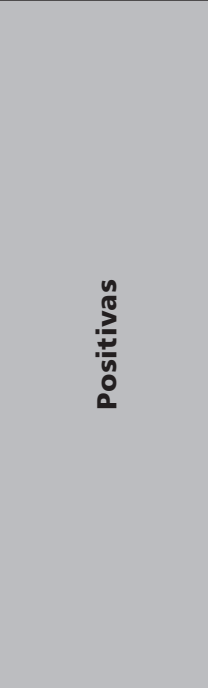 } & \multirow[b]{2}{*}{ A } & \multirow[b]{2}{*}{ Por ley } & "Porque forma parte del currículum de infantil" \\
\hline & & & $\begin{array}{l}\text { "Porque tengo que programar actividades para conseguir los objetivos } \\
\text { marcados por ley" }\end{array}$ \\
\hline & \multirow[t]{2}{*}{ B } & \multirow{2}{*}{$\begin{array}{l}\text { Imprescindible } \\
\text { para el desarrollo }\end{array}$} & $\begin{array}{l}\text { "Porque la música es muy importante para los niños y les ayuda } \\
\text { a centrarse, relajarse, etc." }\end{array}$ \\
\hline & & & "Es importante para el desarrollo integral del niño" \\
\hline & \multirow{3}{*}{ C } & \multirow{3}{*}{$\begin{array}{l}\text { Se incluye en } \\
\text { la programación } \\
\text { de aula }\end{array}$} & $\begin{array}{l}\text { "Tenemos una sesión mínima en la semana exclusiva para audiciones e } \\
\text { instrumentación. Todos los días en la rutina, cantamos" }\end{array}$ \\
\hline & & & $\begin{array}{l}\text { "Incluyo la música en mi horario escolar aparte de utilizarla como } \\
\text { recurso didáctico" }\end{array}$ \\
\hline & & & $\begin{array}{l}\text { "Porque los contenidos y objetivos están recogidos en una programación } \\
\text { previa, la cual cumplo" }\end{array}$ \\
\hline & \multirow[b]{2}{*}{ D } & \multirow{2}{*}{$\begin{array}{l}\text { Enseñanza } \\
\text { globalizada }\end{array}$} & "Porque es un aprendizaje que apoya y complementa el resto" \\
\hline & & & $\begin{array}{l}\text { "Porque es importante conseguir una educación global del niño y un aspecto } \\
\text { para trabajar todo es la educación musical" }\end{array}$ \\
\hline \multirow{15}{*}{ 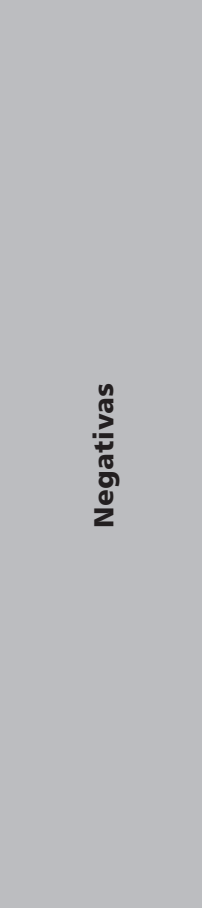 } & \multirow{3}{*}{ E } & \multirow{3}{*}{$\begin{array}{l}\text { Especialista } \\
\text { de música }\end{array}$} & $\begin{array}{l}\text { "El especialista entra en el aula y trabaja según lo propuesto } \\
\text { por las editoriales" }\end{array}$ \\
\hline & & & "El especialista entra en el aula de acuerdo con la programación" \\
\hline & & & $\begin{array}{l}\text { "Porque solo lo hacemos en la sesión semanal de música conforme lo } \\
\text { plantea el Decreto y con la presencia del especialista en todo momento" }\end{array}$ \\
\hline & \multirow{6}{*}{$\mathbf{F}$} & \multirow{6}{*}{$\begin{array}{l}\text { Falta de recursos } \\
\text { y formación }\end{array}$} & "Porque no me siento capacitada" \\
\hline & & & "Por falta de formación y en algunos casos de material" \\
\hline & & & "Dificultades [de] material y organizativas" \\
\hline & & & "Muchas veces no sé cómo hacerlo" \\
\hline & & & "Por falta de recursos y de conocimiento" \\
\hline & & & "No siempre las condiciones para trabajar la música son las adecuadas" \\
\hline & \multirow{3}{*}{ G } & \multirow{3}{*}{$\begin{array}{l}\text { Prioridad } \\
\text { a otras áreas }\end{array}$} & $\begin{array}{l}\text { "En } 5 \text { anys (educación infantil) tot es planteja per a l'aprenentatge de la } \\
\text { lectoescriptura (em falta temps)" }\end{array}$ \\
\hline & & & "Tiendo a darles más importancia a otras asignaturas" \\
\hline & & & "Porque hay muchos aspectos qué trabajar y a veces falta tiempo" \\
\hline & \multirow{3}{*}{ H } & \multirow{3}{*}{$\begin{array}{l}\text { Desconocimiento } \\
\text { legislativo }\end{array}$} & "No lo conozco bien" \\
\hline & & & "No lo he leído" \\
\hline & & & "Ahora mismo no recuerdo en qué consiste" \\
\hline
\end{tabular}

Fuente: elaboración propia

Los datos obtenidos en la tabla 4 delatan que las valoraciones de la mayoría de los tutores que lo trabajan "siempre" y "casi siempre" eran positivas, en cambio, los que la trabajan "a veces", "casi nunca" y "nunca" alegaron posturas negativas (concretamente los que pertenecen al grupo 2). Estos datos cualitativos son reveladores para la investigación, porque reafirman y sustentan los datos concluyentes cuantitativos. 
Tabla 4

Porcentajes de ambos grupos de tutores en relación con sus valoraciones (tabla 3)

\begin{tabular}{|c|c|c|c|c|c|c|c|c|c|c|c|c|c|c|c|c|c|c|}
\hline & \multicolumn{9}{|c|}{ Grupo $1(N=60)$} & \multicolumn{9}{|c|}{ Grupo $2(N=35)$} \\
\hline & A & B & C & D & $\mathbf{E}$ & $\mathbf{F}$ & G & H & NC & $\mathbf{A}$ & B & C & D & $\mathbf{E}$ & $\mathbf{F}$ & G & H & NC \\
\hline Nunca & 0,0 & 0,0 & 0,0 & 0,0 & 0,0 & 0,0 & 0,0 & 0,0 & 0,0 & 0,0 & 0,0 & 0,0 & 0,0 & 5,3 & 0,0 & 0,0 & 2,1 & 5,3 \\
\hline Casi nunca & 0,0 & 0,0 & 0,0 & 0,0 & 0,0 & 0,0 & 0,0 & 0,0 & 1,1 & 0,0 & 0,0 & 0,0 & 0,0 & 1,1 & 1,1 & 0,0 & 1,1 & 5,3 \\
\hline A veces & 0,0 & 0,0 & 0,0 & 2,1 & 1,1 & 6,3 & 3,1 & 0,0 & 6,3 & 2,1 & 0,0 & 0,0 & 1,1 & 2,1 & 0,0 & 2,1 & 0,0 & 1,1 \\
\hline Casi siempre & 7,4 & 5,3 & 3,1 & 2,1 & 3,1 & 1,1 & 0,0 & 0,0 & 5,3 & 0,0 & 0,0 & 0,0 & 0,0 & 0,0 & 0,0 & 0,0 & 0,0 & 0,0 \\
\hline Siempre & 2,1 & 1,1 & 2,1 & 0,0 & 1,1 & 0,0 & 0,0 & 0,0 & 3,1 & 0,0 & 0,0 & 0,0 & 0,0 & 0,0 & 0,0 & 0,0 & 0,0 & 0,0 \\
\hline NS/NC & 0,0 & 0,0 & 0,0 & 0,0 & 0,0 & 0,0 & 0,0 & 1,1 & 5,3 & 0,0 & 0,0 & 0,0 & 0,0 & 1,1 & 0,0 & 0,0 & 1,1 & 5,3 \\
\hline Total (95) & 9,5 & 6,4 & 5,2 & 4,2 & 5,3 & 7,4 & 3,1 & 1,1 & 21,1 & 2,1 & 0,0 & 0,0 & 1,1 & 9,6 & 1,1 & 2,1 & 4,3 & 17 \\
\hline
\end{tabular}

Fuente: elaboración propia

Asimismo, teniendo en cuenta las dos posturas (positiva y negativa) que se especificaron en la síntesis del primer objetivo de este estudio, se puede decir que los elevados porcentajes de ambos grupos delatan el interés (postura positiva) y desinterés (postura negativa) de los tutores por impartir la enseñanza musical en general. Los porcentajes elevados del grupo 1 se centran en las posturas positivas: "Por ley" (9,5\%), "Imprescindible" (6,4\%), "Incluye en la programación de aula" (5,2\%) y "Enseñanza globalizada" (4,2\%). En cambio, los porcentajes más elevados del grupo 2 radican en las posturas negativas: "Especialista de música" (9,6\%) y "Desconocimiento" (4,3\%).

Según los resultados obtenidos a lo largo del análisis de todo el objetivo, se destaca un desinterés por trabajar la discriminación auditiva a medida que los tutores se desvinculan de impartir el lenguaje musical en su praxis docente (tabla 5 y gráfico 5).

Tabla 5

Porcentajes y frecuencias del tiempo aproximado en trabajar la discriminación auditiva en relación con la práctica del lenguaje musical

\begin{tabular}{|c|c|c|c|c|c|c|c|c|c|c|c|c|c|c|}
\hline & \multicolumn{13}{|c|}{ Discriminación auditiva } \\
\hline & & \multicolumn{10}{|c|}{ Grupo 1} & \multirow{2}{*}{\multicolumn{2}{|c|}{ Grupo 2}} & \multirow{3}{*}{$\begin{array}{l}\text { Total } \\
\text { (95) }\end{array}$} \\
\hline & & \multicolumn{2}{|c|}{$30 \mathrm{~min} /$ día } & \multicolumn{2}{|c|}{$2 \mathrm{~h} / \mathrm{sem}$} & \multicolumn{2}{|c|}{$1 \mathrm{~h} / \mathrm{sem}$} & \multicolumn{2}{|c|}{$\begin{array}{l}30 \mathrm{~min} / \\
\mathrm{sem}\end{array}$} & \multicolumn{2}{|c|}{ NS/NC } & & & \\
\hline & & $\mathbf{F}$ & (\%) & $\mathbf{F}$ & (\%) & $\mathbf{F}$ & (\%) & $\mathbf{F}$ & $(\%)$ & $\mathbf{F}$ & (\%) & $\mathbf{F}$ & (\%) & \\
\hline \multirow{6}{*}{ 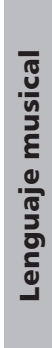 } & Nunca & 0 & 0,0 & 0 & 0,0 & 0 & 0,0 & 0 & 0,0 & 0 & 0,0 & 12 & 12,6 & 12,6 \\
\hline & Casi nunca & 0 & 0,0 & 0 & 0,0 & 0 & 0,0 & 0 & 0,0 & 1 & 1,1 & 8 & 8,4 & 9,5 \\
\hline & A veces & 4 & 4,2 & 2 & 2,1 & 7 & 7,4 & 5 & 5,3 & 0 & 0,0 & 8 & 8,4 & 27,4 \\
\hline & Casi siempre & 7 & 7,4 & 6 & 6,3 & 7 & 7,4 & 5 & 5,3 & 1 & 1,1 & 0 & 0,0 & 27,4 \\
\hline & Siempre & 2 & 2,1 & 5 & 5,3 & 0 & 0,0 & 1 & 1,1 & 1 & 1,1 & 0 & 0,0 & 9,6 \\
\hline & NS/NC & 0 & 0,0 & 2 & 2,1 & 0 & 0,0 & 2 & 2,1 & 2 & 2,1 & 7 & 7,4 & 13,7 \\
\hline \multicolumn{2}{|c|}{ Total (95) } & 13 & 13,7 & 15 & 15,8 & 14 & 14,8 & 13 & 13,8 & 5 & 5,4 & 35 & 36,8 & 100,0 \\
\hline
\end{tabular}

Fuente: elaboración propia 
Gráfico 5

Porcentaje del tiempo aproximado en trabajar la discriminación auditiva en relación con la práctica del lenguaje musical

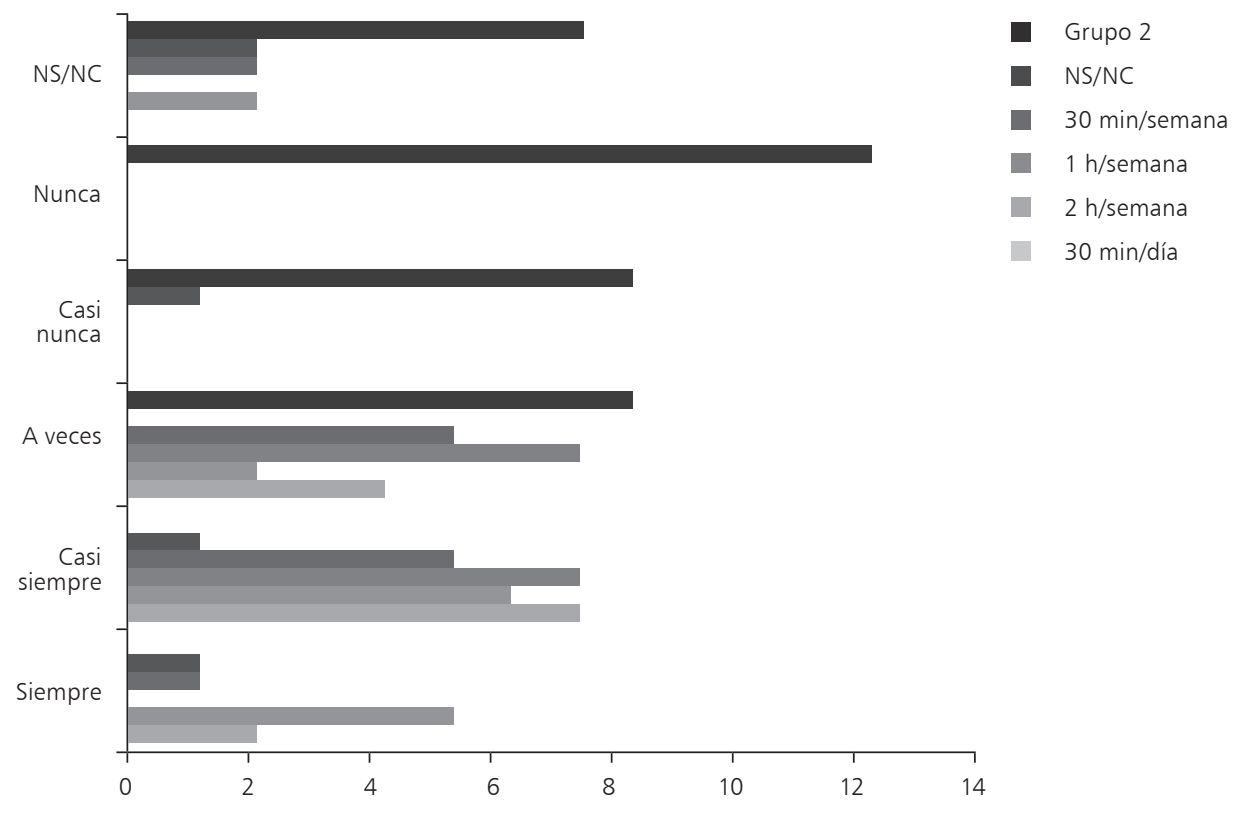

Fuente: elaboración propia

Concretamente, más de la mitad $(21,1 \%)$ de los $36,9 \%$ tutores que testifican trabajar el lenguaje musical con una frecuencia alta ("siempre" y "casi siempre") también tienen interés por trabajar la discriminación auditiva. Estos alegan practicarla entre 2 y 3 horas a la semana. Seguidamente, del $27,4 \%$ de tutores que cita trabajar "a veces" dicho lenguaje, menos de una cuarta parte $(6,3 \%)$ le da importancia a la discriminación auditiva por practicarla en la misma cantidad de tiempo que los tutores anteriores. Finalmente, hay una nulidad en el trabajo de esta habilidad de aquellos tutores que manifiestan no trabajar "casi nunca" o "nunca" este lenguaje $(22,1 \%)$. Así pues, cuanto más interés se tiene en enseñar música, mayor es la importancia que se da a la discriminación auditiva en particular.

No obstante, a lo largo del cuestionario, el 14,9\% argumentó que la enseñanza musical tendría que ser impartida solo por los especialistas de música (tabla 6).

Tabla 6

Aportes de los tutores

"Por supuesto que necesitaría más formación para hacerlo, pero considero que esta área la debe de impartir el especialista de música puesto que es fundamental para los niños de esta etapa y yo, como docente de educación infantil, no considero tener un buen nivel, un especialista de música la puede hacer mucho mejor"

\begin{tabular}{l}
\hline "Debería de impartirla un músico, pero soy consciente [de] que necesito una formación básica" \\
"Considero que, en esta etapa de infantil, igual que en primaria, deberían de entrar los especialistas (inglés, música, \\
educación física)" \\
\hline "La música debe ser impartida por los especialistas en la materia, ya que son los que tienen la adecuada formación" \\
"Debería ser obligatorio por ley que el especialista de música entrase en el aula de educación infantil" \\
"Que haya especialistas de música en infantil y así no haremos chapuzas (...)"
\end{tabular}

Fuente: elaboración propia 
Este dato denota inseguridad y poca confianza por parte del profesorado de educación infantil para impartir el lenguaje musical a raíz de la escasa formación musical que recibió tanto inicial como permanentemente para llevar a cabo una enseñanza musical de calidad a sus alumnos. Sin embargo, a la mitad de los tutores le interesaría dar más música en sus clases (48,4\%). Además, el $89,8 \%$ solicitó recibir más cursos de formación en educación musical destinados para ellos.

En segundo lugar, tras analizar los diferentes momentos considerados ideales por los docentes para trabajar la discriminación auditiva, se destacaron dos objetivos de uso:

a. Motivar y guiar la atención del niño con el fin de prepararlo para hacer alguna actividad que requiera concentración (al principio del día y antes de una actividad cognitiva): el 52,6\%.

b. Relajar al niño después de haber hecho una actividad cognitiva para despejarse (al final del día, después de una actividad cognitiva y como premio puntual): el 39\%.

Por tanto, según los datos obtenidos, los tutores ven la discriminación auditiva como una manera idónea para centrar, motivar y guiar la atención del niño en el inicio de las tareas que requieran cierta concentración.

En tercer lugar, el 63,2\% de tutores aseguró incluir la discriminación auditiva dentro de su programación didáctica frecuentemente (el 35,8\%) o a veces (el 27,4\%). En cambio, el 36,8\% de los tutores no suele introducirla. Este dato fue significativo para el estudio, ya que manifiesta el interés de más de la mitad de la muestra en ubicar la música, en concreto la discriminación auditiva, dentro de su praxis docente y relacionarla con el resto de materias curriculares.

\section{Valoraciones del objetivo II}

Este objetivo versa en conocer cómo los tutores de infantil desarrollan la discriminación auditiva en su praxis por medio de las audiciones musicales. Por consecuencia, se identificó la frecuencia con que trabajan cada parámetro musical, las actividades musicales que llevan a cabo, los soportes musicales utilizados y cuáles son los estilos musicales y los materiales didácticos elegidos por los tutores para desarrollar esta habilidad.

Con respecto a la muestra utilizada para el análisis de los resultados de este objetivo, solo se tuvieron en cuenta los maestros que impartían el lenguaje musical en su actividad profesional (grupo 1) y se excluyeron aquellos que no lo llevaban a cabo (grupo 2). La muestra filtrada fue un total de 60 tutores $(63,2 \%$ de la muestra global).

\section{Parámetros musicales}

Según Joaquim Miranda-Pérez (2003) y Lucía Inés Lahoza-Estarriaga (2012), para trabajar las audiciones musicales es necesario comenzar discriminando todos sus elementos por separado, con el fin de ir agrupándolos de modo paulatino en otros niveles de educación. Así, pues, partiendo de esta idea pedagógica, se tuvieron en cuenta 19 aspectos musicales que pueden ser analizados en las audiciones musicales. La tabla 7 contempla la media aritmética ${ }^{5}$ de cada elemento musical por niveles y por ciclo con el fin de conocer cuáles son los más trabajados por los tutores en la etapa infantil para desarrollar el oído mediante la discriminación auditiva.

5 Para calcular las medias aritméticas se tuvieron en cuenta los siguientes grados de preferencia: 0 "No sabe/no contesta", 1 "Nunca", 2 "Casi nunca", 3 "A veces", 4 "Casi siempre" y 5 "Siempre". 
Tabla 7

Medias aritméticas de los parámetros musicales por nivel y ciclo

\begin{tabular}{|c|c|c|c|c|c|}
\hline & \\
\hline & & 1er Nivel $^{\text {en }}$ & $2^{\circ}$ Nivel & $3^{\text {er Nivel }}$ & Ciclo \\
\hline \multicolumn{2}{|c|}{ Duración } & 3,25 & 3,95 & 3,61 & 3,62 \\
\hline \multicolumn{2}{|c|}{ Pulso } & 1,85 & 2,14 & 2,44 & 2,13 \\
\hline \multicolumn{2}{|c|}{ Altura } & 3,15 & 3,18 & 3,06 & 3,13 \\
\hline \multicolumn{2}{|c|}{ Movimiento melódico } & 2,35 & 2,68 & 1,94 & 2,35 \\
\hline \multicolumn{2}{|c|}{ Intensidad } & 3,90 & 3,86 & 3,94 & 3,90 \\
\hline \multicolumn{2}{|c|}{ Matices dinámicos } & 1,90 & 2,59 & 2,28 & 2,27 \\
\hline \multirow{4}{*}{$\frac{\underline{o}}{\underline{\underline{0}}}$} & Sonidos del entorno & 4,25 & 3,59 & 4,00 & 3,93 \\
\hline & Cuerpo y voces & 4,25 & 3,23 & 4,06 & 3,82 \\
\hline & Cotidiáfonos & 2,75 & 2,32 & 2,94 & 2,65 \\
\hline & Instrumentos musicales & 3,20 & 3,23 & 3,06 & 3,17 \\
\hline \multicolumn{2}{|c|}{ Textura } & 1,95 & 1,77 & 2,00 & 1,90 \\
\hline \multicolumn{2}{|c|}{ Localizar la fuente sonora } & 3,25 & 2,64 & 2,89 & 2,92 \\
\hline \multicolumn{2}{|c|}{ Velocidad } & 3,55 & 3,86 & 3,89 & 3,77 \\
\hline \multicolumn{2}{|c|}{ Matices agógicos } & 1,90 & 2,00 & 2,22 & 2,03 \\
\hline \multicolumn{2}{|c|}{ Sonido/Silencio/Ruido } & 4,00 & 4,09 & 3,67 & 3,93 \\
\hline \multicolumn{2}{|c|}{ Carácter } & 3,25 & 3,45 & 3,33 & 3,35 \\
\hline \multicolumn{2}{|c|}{ Forma } & 1,20 & 1,41 & 1,89 & 1,48 \\
\hline \multicolumn{2}{|c|}{ Ritmo } & 3,55 & 3,18 & 3,39 & 3,37 \\
\hline \multicolumn{2}{|c|}{ Melodía } & 2,90 & 2,82 & 3,17 & 2,95 \\
\hline \multicolumn{2}{|c|}{ Número } & 20 & 22 & 18 & 60 \\
\hline
\end{tabular}

Fuente: elaboración propia

En este sentido, los resultados obtenidos han mostrado que la discriminación del sonido/silencio/ruido y los sonidos del entorno son los más utilizados por el ciclo. Posteriormente, los elementos con una frecuencia menos elevada son la intensidad, los sonidos del cuerpo y las voces, la velocidad, la duración, el ritmo, el carácter, los instrumentos musicales y la altura. Seguidamente, aquellos que son valorados con una frecuencia intermedia son la melodía, la localización de la fuente sonora, los cotidiáfonos, el movimiento melódico, los matices dinámicos, el pulso y los matices agógicos. Finalmente, la textura y la forma son los menos trabajados en las aulas.

\section{Actividades musicales}

Las actividades musicales escogidas para analizar el segundo objetivo fueron extraídas de propuestas didácticas de autores (Lahoza, 2012; Malagarriga \& Valls, 2003; Palacios, 2011, entre otros) que las consideran idóneas para trabajar la escucha comprensiva y la discriminación auditiva por medio de la audición activa.

Los resultados obtenidos en el estudio dejaron constancia de que la expresión corporal, el canto y la dramatización son las actividades más utilizadas por los tutores de infantil para trabajar esta habilidad (tabla 8 y gráfico 6): 
Tabla 8

Medias aritméticas de las actividades musicales por nivel y ciclo

\begin{tabular}{l|c|c|c|c}
\cline { 2 - 5 } & 1er Nivel & 20 Nivel & 3er Nivel & Ciclo \\
\hline De expresión corporal & 3,45 & 3,73 & 3,39 & 3,53 \\
\hline De dramatización & 3,20 & 3,18 & 2,83 & 3,08 \\
\hline De canto & 3,25 & 3,36 & 3,94 & 3,50 \\
\hline De expresión instrumental & 2,40 & 2,14 & 2,22 & 2,25 \\
\hline De pintar y dibujar & 2,30 & 2,27 & 2,78 & 2,43 \\
\hline De ordenar símbolos, gráficos... & 1,65 & 1,41 & 1,67 & 1,57 \\
\hline De agrupar sonidos iguales & 1,75 & 1,59 & 1,94 & 1,75 \\
\hline De reconocer series de sonidos & 2,15 & 2,18 & 2,11 & 2,15 \\
\hline Número & 20 & 22 & 18 & 60 \\
\hline \hline
\end{tabular}

Fuente: elaboración propia

Gráfico 6

Comparación de medias aritméticas de las actividades musicales por niveles

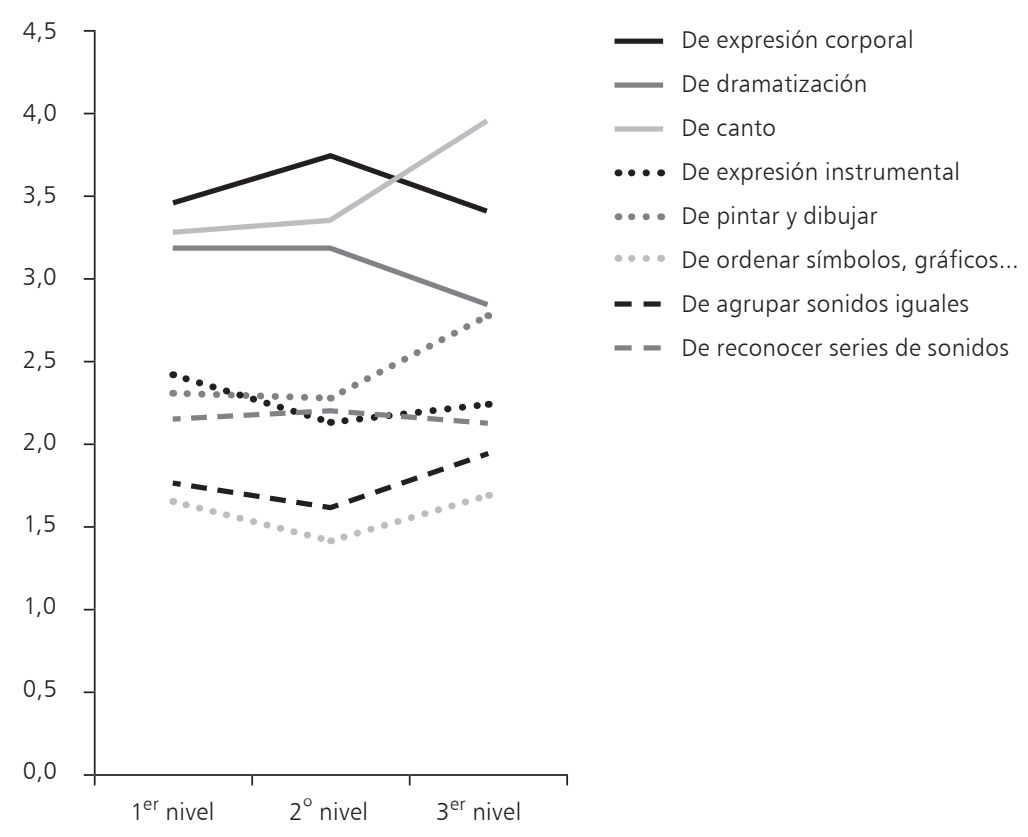

Fuente: elaboración propia

\section{Soportes musicales}

Es interesante identificar cuáles son los soportes musicales que suelen utilizar los maestros de infantil en el momento de trabajar la discriminación auditiva para saber en qué medida los alumnos viven y experimentan el sonido en directo. Algunos autores (Raymond Toraille citado en Muñoz-Rubio, 2007; Schafer, 1994) aluden que escuchar sonidos en directo creados por los alumnos y por el propio maestro evoca un ambiente cautivador y desarrolla la inteligencia emocional tanto interpersonal como intrapersonal. 
Así, pues, según los datos obtenidos en el estudio, más de tres cuartas partes de la muestra filtrada $(78,3 \%)$ utilizan las audiciones grabadas para llevarlo a cabo, seguido de sonidos producidos por el cuerpo $(60 \%)$, el canto in situ (61,6\%), los sonidos in situ del entorno (50\%) y sonidos in situ de instrumentos musicales (38,3\%). Seguidamente, la tabla 9 y el gráfico 7 ilustran los soportes musicales utilizados por los tutores en cada nivel y ciclo.

Tabla 9

Medias aritméticas de los soportes musicales utilizados por nivel y por ciclo

\begin{tabular}{lccccc} 
& 1er Nivel & $\mathbf{2}^{\mathbf{0}}$ Nivel & $\mathbf{3}^{\text {er Nivel }}$ & Ciclo \\
\hline Sonidos in situ del entorno & 3,05 & 3,27 & 3,17 & 3,17 \\
Sonidos producidos por el cuerpo & 3,75 & 3,59 & 3,67 & 3,67 \\
El canto in situ & 3,30 & 3,36 & 3,28 & 3,32 \\
Sonidos in situ de instrumentos musicales o cotidiáfonos & 3,40 & 2,59 & 2,50 & 2,83 \\
Audiciones musicales grabadas & 4,10 & 4,18 & 4,06 & 4,12 \\
Número & 20 & 22 & 18 & 60 \\
\hline \hline
\end{tabular}

Fuente: elaboración propia

Gráfico 7

Comparación de medias aritméticas de los soportes musicales por niveles

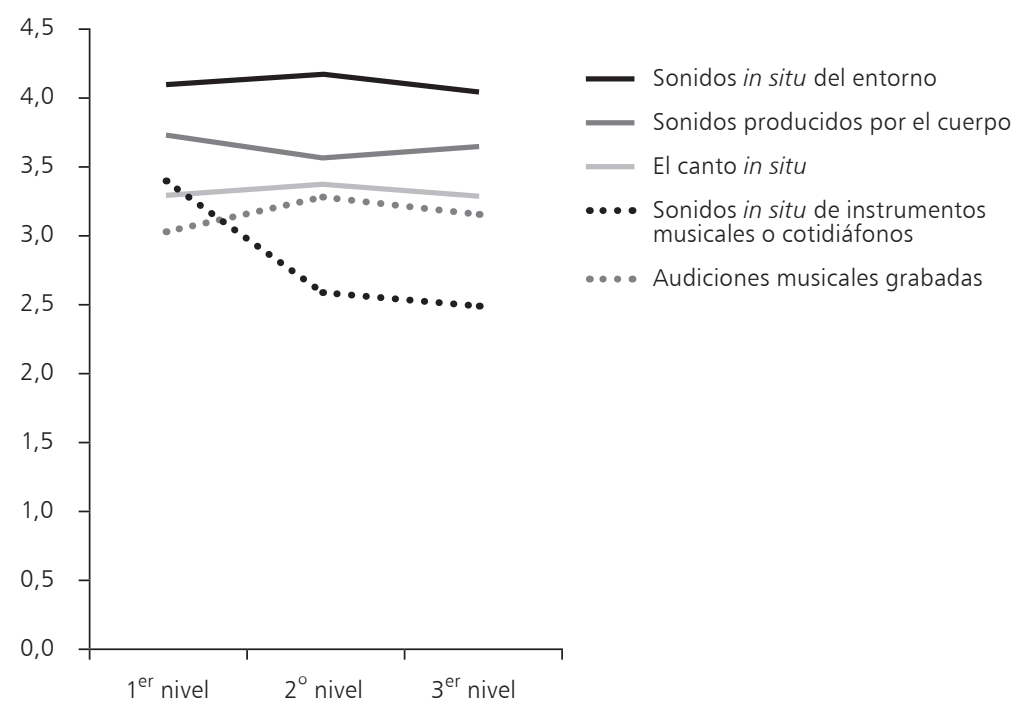

Fuente: elaboración propia

Estilos musicales

El tipo de música que escuchan los niños diariamente es un dato importante para valorar, ya que de ello dependerán su sensibilidad musical y su visión crítica y estética a lo largo de su etapa escolar. El dato más significativo fue el altísimo porcentaje de tutores (95\%) que utilizan obras compuestas destinadas a la enseñanza (música didáctica) en sus alumnos, seguida de la música clásica y operística (76,6\%). En tercer lugar, el folclórico 
fue el estilo musical valorado por el $43,3 \%$ de los tutores. Seguidamente, las obras compuestas propias y de jazz obtuvieron la misma valoración $(11,6 \%)$ y, por último, el flamenco $(0 \%)$. Este hecho evidencia el escaso tratamiento que recibe la música cultural e intercultural dentro de la educación infantil (tabla 10).

Tabla 10

Frecuencias y porcentajes de los estilos musicales por niveles y por ciclo

\begin{tabular}{|c|c|c|c|c|c|c|c|}
\hline \multicolumn{2}{|c|}{$1^{\text {er Nivel }}$} & \multicolumn{2}{|c|}{$2^{\circ}$ Nivel } & \multicolumn{2}{|c|}{$\mathbf{3}^{\text {er }}$ Nivel } & \multicolumn{2}{|c|}{ Ciclo } \\
\hline $\mathbf{F}$ & (\%) & $\mathbf{F}$ & (\%) & $\mathbf{F}$ & (\%) & $\mathbf{F}$ & (\%) \\
\hline 20 & 27,4 & 21 & 29,6 & 16 & 26,7 & 57 & 95,0 \\
\hline 15 & 20,5 & 16 & 22,5 & 15 & 25,0 & 46 & 76,6 \\
\hline 7 & 9,6 & 10 & 14,1 & 9 & 15,0 & 26 & 43,3 \\
\hline 9 & 12,3 & 7 & 9,9 & 5 & 8,3 & 21 & 35,0 \\
\hline 9 & 12,3 & 5 & 7,0 & 5 & 8,3 & 19 & 31,6 \\
\hline 7 & 9,6 & 7 & 9,9 & 4 & 6,7 & 18 & 30,0 \\
\hline 2 & 2,7 & 2 & 2,8 & 3 & 5,0 & 7 & 11,6 \\
\hline 4 & 5,5 & 1 & 1,4 & 2 & 3,3 & 7 & 11,6 \\
\hline 0 & 0,0 & 2 & 2,8 & 1 & 1,7 & 3 & 5,0 \\
\hline 0 & 0,0 & 0 & 0,0 & 0 & 0,0 & 0 & 0,0 \\
\hline \multicolumn{2}{|c|}{20} & \multicolumn{2}{|c|}{22} & \multicolumn{2}{|c|}{18} & \multicolumn{2}{|c|}{60} \\
\hline
\end{tabular}

Fuente: elaboración propia

\section{Materiales didácticos}

Por último, conocer los materiales didácticos utilizados por los maestros de infantil es un dato claro del valor y la importancia que dan a cada uno de ellos. En este sentido, casi la totalidad de los maestros (73,3\%) utilizan más los audiovisuales en sus clases en comparación a los diseñados para la estimulación auditiva: los gráficos (el 11,6\%) y los musicogramas (el 23,3\%) (tabla 11).

Tabla 11

Frecuencias y porcentajes de los materiales didácticos por nivel y por ciclo

\begin{tabular}{|c|c|c|c|c|c|c|c|c|}
\hline & \multicolumn{2}{|c|}{ 1er Nivel } & \multicolumn{2}{|c|}{$2^{\circ}$ Nivel } & \multicolumn{2}{|c|}{$3^{\text {er Nivel }}$} & \multicolumn{2}{|c|}{ Ciclo } \\
\hline & $\mathbf{F}$ & (\%) & $\mathbf{F}$ & (\%) & $\mathbf{F}$ & (\%) & $\mathbf{F}$ & (\%) \\
\hline Audiovisuales & 16 & 27,6 & 15 & 26,8 & 13 & 27,7 & 44 & 73,3 \\
\hline Cuentos sonoros & 14 & 24,1 & 10 & 17,9 & 11 & 23,4 & 35 & 58,3 \\
\hline Fichas de editoriales & 13 & 22,4 & 7 & 12,5 & 8 & 17,0 & 28 & 46,6 \\
\hline Fichas propias & 8 & 13,8 & 11 & 19,6 & 4 & 8,5 & 23 & 38,3 \\
\hline Musicogramas & 3 & 5,2 & 6 & 10,7 & 5 & 10,6 & 14 & 23,3 \\
\hline Otros & 3 & 5,2 & 2 & 3,6 & 3 & 6,4 & 8 & 13,3 \\
\hline Gráficos & 1 & 1,7 & 3 & 5,4 & 3 & 6,4 & 7 & 11,6 \\
\hline Ninguno & 0 & 0,0 & 2 & 3,6 & 0 & 0,0 & 2 & 3,0 \\
\hline Número & \multicolumn{2}{|c|}{20} & \multicolumn{2}{|c|}{22} & \multicolumn{2}{|c|}{18} & \multicolumn{2}{|c|}{60} \\
\hline
\end{tabular}

Fuente: elaboración propia 
Valoraciones del objetivo III

Según el Decreto 38/2008 (España, Conselleria de Educación, Comunidad Valenciana, 2008), los docentes de esta etapa educativa pueden recibir la ayuda pertinente en cada caso por el especialista si lo necesitan. Por consiguiente, el tercer objetivo de la investigación se centró en identificar la ayuda que los maestros de infantil reciben del maestro especialista en Educación Musical de Primaria para impartir el Lenguaje Musical en su praxis.

Con respecto a la muestra utilizada para el análisis de los resultados de este objetivo, solo se tuvo en cuenta los maestros del grupo 1 (63,2\% de la muestra global). La tabla 12 relaciona el grado en que trabajan los tutores dicho lenguaje con el nivel de ayuda que consideran que reciben del especialista de música.

Tabla 12

Frecuencias y porcentajes de la muestra filtrada: Lenguaje Musical y ayuda del especialista de música

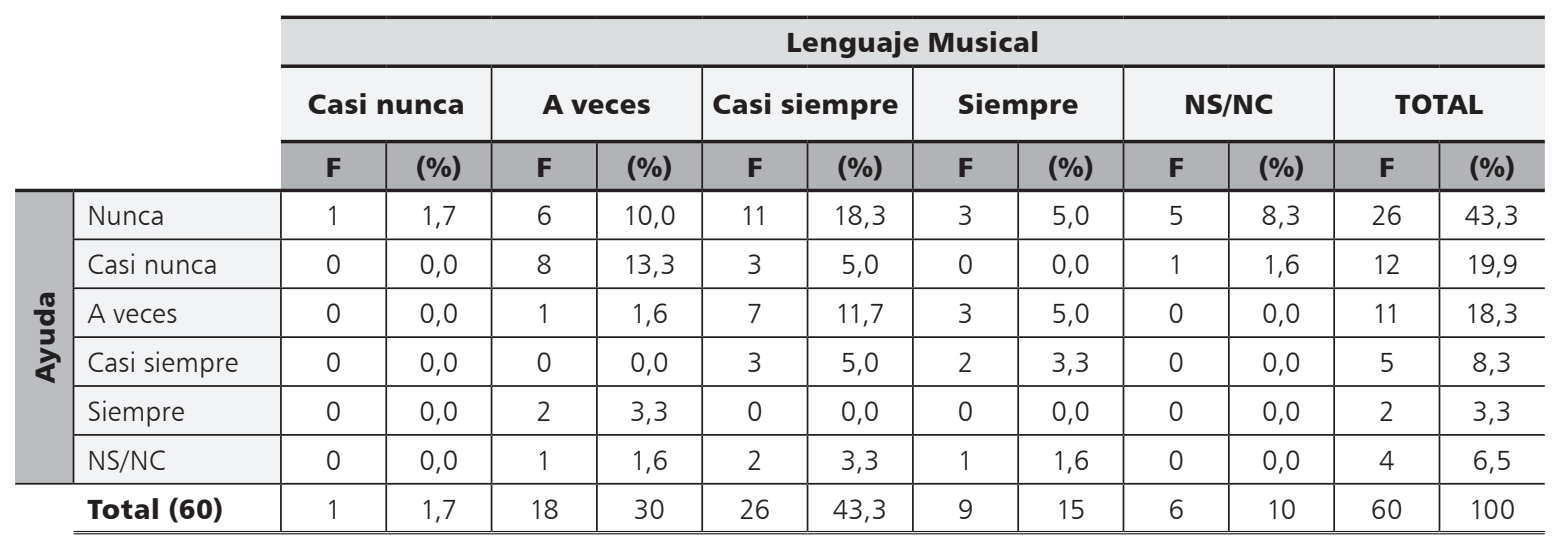

Fuente: elaboración propia

El resultado más impactante fue el escaso apoyo que los especialistas de música ofrecen a los tutores de infantil. Más de la mitad, concretamente el $88,3 \%$ de los tutores, trabajan "a veces", "casi siempre" y "siempre" el lenguaje musical y, en consecuencia, deberían recibir más atención por parte de estos, pero solamente el 11,6\% testificó que es asesorado "siempre" (3,3\%), "casi siempre" (8,3\%), y "a veces" (18,3\%) por el especialista.

Este hallazgo reafirma los resultados de la investigación de María de los Ángeles López de la Calle-Sampedro (2007), al conocer que la mayoría del profesorado de esta etapa no recibía el apoyo necesario por el especialista. Así, pues, esta autora concluye: "Por lo tanto, se puede decir que un gran número de aulas de educación infantil a las que pertenecen estos profesores, no cuentan con esta ayuda básica que complementa y enriquece el currículum de música" (p. 242).

\section{Conclusiones}

Las principales conclusiones que se extraen de los resultados obtenidos por las valoraciones de los tutores de $2^{\circ}$ ciclo de educación infantil de los colegios públicos de Valencia ponen en relieve que menos de la mitad de la muestra (36,9\%) alega impartir el lenguaje musical en su práctica docente de manera significativa. Además, solamente el $63,2 \%$ de estos docentes incluye el trabajo de la discriminación auditiva en su programación didáctica: el 21,1\% la practica entre 2 y 3 horas semanales. Con respecto al asesoramiento por parte de los especialistas de música, solamente el $11,6 \%$ lo recibe de manera significativa. 
Teniendo en cuenta estos resultados, llegamos a la conclusión de que los niños de $2^{\circ}$ ciclo de infantil en las escuelas públicas de Valencia reciben una escasa estimulación de la capacidad auditiva a partir del desarrollo de la habilidad de discriminación auditiva por parte los tutores.

En segundo lugar, casi la totalidad de la muestra (89,8\%) solicita una mayor oferta de los cursos de formación musicales permanentes, adaptados y diseñados tanto para ellos como para la etapa en que imparten docencia. No obstante, el 14,9\% considera que es más favorable que sean solamente los especialistas de música quienes trabajen el lenguaje musical, en general, y la discriminación auditiva, en particular, a partir de las audiciones musicales en la etapa infantil. Sin embargo, el 48,4\% testifica que les gustaría trabajar la discriminación auditiva a partir de las actividades audiomusicales porque lo considera esencial para el desarrollo integral del alumno.

En tercer lugar, los datos relatan que, de los tutores que lo llevan a la práctica, el 52,6\% suele potenciarlo antes de realizar una actividad cognitiva para preparar la atención y la concentración del alumno.

En cuarto lugar, los cuatro parámetros musicales más utilizados por los tutores para desarrollar la discriminación auditiva son el sonido/silencio/ ruido; los sonidos del entorno; la intensidad; y los sonidos del cuerpo y las voces. Las actividades audiomusicales más afines son la expresión corporal y el canto, destacando con un menor porcentaje aquellas diseñadas para la estimulación de la vía auditiva como el uso de instrumentos musicales y la notación no convencional. Los soportes que más suelen utilizar son las grabaciones de canciones con un texto didáctico, en contra de otros estilos musicales (el jazz y el flamenco).

Los datos manifestados en la investigación demuestran la escasa formación musical que tienen los tutores en el ámbito musical para desarrollar la discriminación auditiva en sus alumnos.

A modo de prospectiva, la línea de investigación que se deja abierta para futuros trabajos es la de exigir la elaboración de materiales y recursos musicales, así como confeccionar guías metodológicas que ayuden a los maestros de infantil a desarrollar la habilidad de la discriminación auditiva por medio de actividades audiomusicales.

\section{Agradecimientos}

Agradecemos a todo el profesorado de educación infantil de los colegios públicos de Valencia que participaron en el cuestionario, especialmente a las tres maestras que lo validaron.

\section{Sobre las autoras}

Ana María Botella-Nicolás es doctora en pedagogía por la Universitat de València, licenciada en musicología y maestra en educación musical. Funcionaria del cuerpo de profesores de enseñanza secundaria en la especialidad de música (actualmente en excedencia). Profesora del departamento de Didáctica de la Expresión Musical, Plástica y Corporal de la Universitat de València. Directora del Aula de Música del Vicerrectorado de Cultura e Igualdad de la Universitat de València, Estudi General, UVEG.

María de los Ángeles Peiró-Esteve es licenciada en psicopedagogía. Máster universitario en investigación en didácticas específicas, especialidad didáctica musical, y maestra en educación musical. Título superior de música en oboe. Maestra interina de educación primaria en el Departament d'Ensenyament de la Generalitat de Catalunya. 


\section{Referencias}

Álvarez, Luis; González-Castro, Paloma; Núñez, José Carlos; González-Pienda, Julio Antonio; Álvarez, David \& Bernardo, Ana Belén (2007). Programa de intervención multimodal para la mejora de los déficits de atención. Psicothema, 19 (4), 591596. Disponible en: http://www.psicothema. com/psicothema.asp?id=3402

Ángel-Alvarado, Rolando (2017). El desarrollo auditivo en la primera infancia: Compendio de evidencias científicas relevantes para el profesorado. Revista Electrónica Educare, 21 (1), 1-8. Disponible en: https://dialnet.unirioja.es/servlet/ articulo?codigo $=5763951$

Bond, Vanessa L. (2012). Music's Representation in Early Childhood Education Journals: A Literature Review. Update: Applications of Research in Music Education, 31 (1), 34-43. Disponible en: http://wcc nafme.weebly.com/uploads/1/2/9/1/12915361/ update-1112-musics_representation_in_early_ childhood_education_jounrals.pdf

Botella-Nicolás, Ana María \& Peiró-Esteve, María de Los Ángeles (2016). Aportaciones de la neurociencia cognitiva a la estimulación auditiva musical de 0 a 6 años. Didácticas Específicas, 15, 6-27. Disponible en: https://revistas.uam.es/di dacticasespecificas/issue/download/645/360

Cañete-S., Óscar (2006). Desorden del procesamiento auditivo central (DPAC). Revista de Otorrinolaringología y Cirugía de Cabeza y Cuello, 66 (3), 263273. Disponible en: http://www.scielo.cl/pdf/orl/ v66n3/art14.pdf

Chaparro-Santana, Tania (2010). Método de lectura Glenn Doman (la Revolución Pacífica). Revista Arista Digital, 3, 1106-1125. Disponible en: http://www.afapna.es/web/aristadigital/archi vos_revista/2010_diciembre_94.pdf

Díaz-Gómez, Maravillas (2005). La Educación Musical en la Escuela y el Espacio Europeo de Educación Superior. Revista Interuniversitaria de Formación del Profesorado, 19 (1), 23-57. Disponible en: http://www.redalyc.org/pdf/274/27419103.pdf

Gimeno-Romero, José Vicente (2014). La audición musical en la Educación Secundaria Obligatoria en la provincia de Valencia: análisis de su tratamiento curricular en los libros de texto (tesis doctoral). Universitat de València, Valencia, España. Disponible en: http://roderic.uv.es/hand le/10550/42774

Ginarte-Arias, Yurelis (2007). La neuroplasticidad como base biológica de la rehabilitación cognitiva. Gerolnfo. Rnps, 2 (1), 1-15. Disponible en: http://www.sld.cu/galerias/pdf/sitios/gericuba/ pub. bases biol._de_reh._cog.pdf
España, Conselleria de Educación, Comunidad Valenciana (3 de abril, 2008). Decreto por el que se establece el currículo del segundo ciclo de la Educación Infantil en la Comunidad Valenciana, 38/2008, 28 de marzo. Diari Oficial de la Comunitat Valenciana, 5734, Sec. I, 5501855048. Disponible en: http://www.dogv.gva.es/ datos/2008/04/03/pdf/2008_3838.pdf

España, Jefatura del Estado (4 de mayo de 1970). Ley 14/1970, de 4 de agosto, General de Educación y Financiamiento de la Reforma educativa (LGE). Boletín Oficial del Estado, BOE, 189, Sec. I, 12525-12546 Disponible en: Disponible en: https://www.boe.es/buscar/doc. php?id=BOEA-1970-852

España, Jefatura del Estado (3 de octubre de 1990). Ley Orgánica 1/1990, de Ordenación General del Sistema Educativo (LOGSE). Boletín Oficial del Estado, BOE, 238, Sec. I, 28927-28942. Disponible en: https://www.boe.es/diario_boe/txt. php?id=BOE-A-1990-24172

España, Jefatura del Estado (4 de mayo de 2006). Ley orgánica de Educación, LOE, 2/2006, 3 de mayo. Boletín Oficial del Estado, BOE, 106, Sec. I, 17158-17207. Disponible en: https://www.boe. es/buscar/doc. php?id=BOE-A-2006-7899

España, Jefatura del Estado (4 de enero, 2007). Real Decreto por el que se establecen las enseñanzas mínimas de segundo ciclo de Educación Infantil, 1630/2006, 29 de diciembre. Boletín Oficial del Estado, BOE, 4, Sec. I, 474-482. Disponible en: https://www.boe.es/diario_boe/txt. php?id=BOE-A-2007-185

España, Jefatura del Estado (10 de diciembre, 2013). Ley orgánica para la mejora de la calidad educativa, LOMCE, 8/2013, 9 de diciembre. Boletín Oficial del Estado, BOE, 295, Sec. I, 97858-97921. Disponible en: https://www.boe.es/diario_boe/ txt.php?id=BOE-A-2013-12886

España, Universitat de València (2000). Resolución de 21 de septiembre de 2000, de la Universidad de València, por la que se ordena publicar el plan de estudios de Maestros-Especialidad de Educación Infantil, adaptado al Real Decreto 779/1998, de 30 de abril, y elaborado al amparo del Real Decreto de Directrices Generales Propias, 1440/1991, de 30 de agosto. Boletín Oficial del Estado, $B O E, 251$, Sec. III, 35937-35946. Disponible en: https://www.boe.es/boe/dias/2000/10/19/pdfs/ A35937-35946.pdf

Estalayo-Alonso, Víctor \& Vega-Martín, María Rosario (2005). La inteligencia auditiva. Técnicas de estimulación prenatal, infantil y permanente. Madrid: Biblioteca Nueva. 
Giráldez-Hayes, Andrea (1996). Relaciones entre la música y otras áreas en educación infantil y primaria. Aula de Innovación Educativa, 55, 9-14

Ibáñez-Martínez, María Julia \& Muro-Jiménez, María Belén (2015). Estimulación de la vía auditiva: materiales. Revista de Educación Inclusiva, 8 (1), 134-147. Disponible en: http://www.revis taeducacioninclusiva.es/index.php/REl/article/ view/124/119

Jáuregui-Huerta, Fernando; García-Estrada, Joaquín; Ramos-Zúñiga, Rodrigo \& Luquín de Anda, Sonia (2014). Mecanismos celulares y moleculares de la plasticidad cerebral y la cognición. En Diego Redolar-Ripoll (ed.). Neurociencia cognitiva, 163178. Madrid: Editorial Médica Panamericana.

Lahoza-Estarriaga, Lucía Inés (2012). La audición musical en los niños. Revista Arista Digital, 25 (26), 1-6. Disponible en: http://www.afapna. com/aristadigital/archivos_revista/2012_noviem bre_0.pdf

López de la Calle-Sampedro, María de los Ángeles (2007). La música en centros de educación infantil 3-6 años de Galicia e Inglaterra, un estudio de su presencia y de las prácticas educativas (tesis doctoral). Universidad de Santiago de Compostela, Santiago de Compostela. Disponible en: https://minerva.usc.es/xmlui/bitstream/ handle/10347/2355/9788497509459_content. pdf? sequence $=1$

López de la Calle-Sampedro, María de los Ángeles (2009). La formación de los maestros de educación infantil para la comprensión de la música y su uso didáctico en Galicia. Revista Electrónica Interuniversitaria de Formación del Profesorado, 12 (1), 107-120. Disponible en: http:// www.aufop.com/aufop/uploaded_files/articu los/1240872964.pdf

Magán-Hervás, Alexandra \& Gértrudix-Barrio, Felipe (2017). Influencia de las actividades audio-musicales en la adquisición de la lectoescritura en niños y niñas de cinco años. Revista Electrónica Educare (Educare Electronic Journal) EISSN, 21 (1), 1-22. Disponible en: https://dialnet.unirioja. es/servlet/articulo?codigo $=5763950$

Malagarriga-Rovira, María Teresa \& Valls-Casanovas, Assumpta (2003). La audición musical en la educación infantil. Barcelona: Ediciones CEAC.

Martins, Margarida Bernabé Lima Brito (2015). Optimización de la discriminación auditiva en alumnado de educación básica y pre-escolar a través de un programa de intervención musical: impacto en su lenguaje y comunicación (tesis doctoral). Universidad de Extremadura, Badajoz, España. Disponible en: http://dehesa.unex.es/ xmlui/handle/10662/4008

Miranda-Pérez, Joaquim (2003). Elaboració d'un Model Multimèdia d'intervenció per a l'educació de l'oïda musical (tesis doctoral). Universitat Autònoma, Barcelona, España. Disponible en: http:// www.tdx.cat/bitstream/handle/10803/5040/jm p1de2.pdf?sequence $=1$

Muñoz-Rubio, Enrique (2007). La comprensión musical de las estéticas del s. XX en el niño (tesis doctoral). Universidad Autónoma de Madrid, Madrid, España.

Palacios, Fernando (2011). Hablar de escuchar: algunas reflexiones sobre música y educación musical. Vitoria-Gasteiz: AgrupArte Producciones.

Piñol-Castro, Montserrat (1999). Valor: aprender a escuchar conscientemente desde el período de la educación infantil. Aula de Innovación Educativa, 79, 20-21.

Pramling-Samuelsson, Ingrid; Carlsson, Maj Asplund; Olsson, Bengt; Pramling, Niklas \& Wallerstedt, Cecilia (2009). The Art of Teaching Children the Arts: Music, Dance and Poetry with Children Aged 2-8 Years Old. International Journal of Early Years Education, 17 (2), 119-135. Disponible en: http://www.tandfonline.com/doi/pdf/10.1080/0 9669760902982323? needAccess $=$ true

Ruiz-Palomo, Esther; Lara-Ortega, Fernando \& Santamaría-Conde, Rosa María (2014). Docencia en percepción auditiva: adaptación a las necesidades de la realidad escolar. Historia y Comunicación Social, 19, 27-40. Disponible en: http://revistas.ucm.es/index.php/HICS/article/ view/44938/42316

Schafer, R. Murray (1975). El rinoceronte en el aula. Buenos Aires: Ricordi Americana.

Schafer, R. Murray (1994). Hacia una educación sonora. 100 ejercicios de adición y producción sonora. Buenos Aires: Pedagogías Musicales Abiertas.

Zenker, Franz \& Barajas de Prat, José Juan (2003). Las funciones auditivas centrales. Auditio: Revista Electrónica de Audiología, 3, 31-42. Disponible en: http://www.auditio.com/docs/File/ vol2/2/020203.pdf 